\title{
Role of Laser and Consciousness on the Nanoparticles: A Bio-Assay Study of Zinc Oxide Nano Particle against Culex quinquifasciatus (Say)
}

\section{Gulwani $\mathrm{D}^{1}$ and Prakash $\mathrm{S}^{2 *}$}

${ }^{1}$ Advanced Parasitology and Quantum Biology Laboratories, India

${ }^{2}$ Department of Zoology, Faculty of Science, Dayalbagh Educational Institute, India

*Corresponding author: Soam Prakash, Department of Zoology, Faculty of Science, Dayalbagh Educational Institute, Agra, India, Email: prakashsoamdei@gmail.com

\section{Research Article \\ Volume 3 Issue 1}

Received Date: January 03, 2020

Published Date: February 04, 2020

DOI: $10.23880 /$ izab-16000202

\section{Abstract}

Can human consciousness affect nano synthesis? Can an observer's effect be observed during experimentation? This is a significant question for future science. In nano-biotechnology, we can incorporate the uses of biological entities in the synthesis of nanoparticles. We have observed that the gel extract of Aloe barbadensis Mill. Integrated with Zinc oxide Nanoparticles (ZnO $\mathrm{NPs}$ ) can actively act against Culex quinquifasciatus (Say) larvae. This is validated by the characterization of synthesized $\mathrm{ZnO}$ NPs via UV-Vis Spectroscopy, XRD and DLS analysis techniques. The efficacy test of synthesized ZnO NPs has been performed against different instars of Culex larvae. By increasing dose concentration of nanoparticles, \% mortality also increased. It is also attempted to study how the amalgamation of Laser and Human consciousness can affect the geometry of nanoparticles, therefore by further experimentation we can predict about subtler energy levels of human attention which can also modify nano synthesis.

Keywords: Consciousness; Laser Oxide Nanoparticles; Culex ququefasciatus

Abbreviations: ZnO NPs: Zinc Oxide Nanoparticles; XRD: X-Ray Diffraction; UV-Vis: Ultraviolet and Visible; DLS: Dynamic Light Scattering.

\section{Introduction}

Can Human consciousness or an observer affect nanosynthesis? This idea needs to be validated by conducting regular experimentation during nanosynthesis. Actually, no such experiment directly has shown evidence of efficacy of human attention in biology. It could be a new direction to allow integration of human energy into the synthesis of nanomaterial; this could provide a basic desideration for conducting new investigations. Various modern control techniques had been applied at a large scale to control mosquito vector-borne diseases but during the course of evolution, many species have developed resistance against the controlling measures. With the rising insecticidal resistance, it became necessary to find an alternative method that should be economical, effective as well as safe for nontarget organisms.

Nano-biotechnology has emerged as a new scientific tool in mosquito control. Green synthesis of nanoparticles using the plant extracts and microbes is safe, environmentfriendly and effective in controlling mosquito vectors [1]. Plant extracts have the interesting ability to reduce the metallic ions which can be utilized in synthesizing metallic nanoparticles. Also, laser irradiation can affect the geometry of nanoparticles as stated by Farooq, et al. [2] as expansion (increase in size) and deformation can take place in the nanodimensions. In our present investigation, we have attempted 
to find out how Laser irradiation with and without human attention and concentration affect the geometry of the $\mathrm{ZnO}$ nanoparticles.

We had previously worked upon the nanosynthesis from different fungal and plant species [3-11] and had also studied the effect of Laser technology on the geometry of Gold nanoparticles [12]. Relevant effect of consciousness in man, mosquito, and microbes have also been studied previously [13-22]. In our present investigation, gel extract of Aloevera has been utilized for the synthesis of Zinc oxide nanoparticles. Applications of Zinc oxide Nanoparticles is widely distributed in various commercial fields like sensors, communication, biology, and medical industry. Due to its crystalline structure, it has been used in biomedical fields and also has properties such as anticancer, anti-bacterial, and anti-fungal. The role of Zinc oxide nanoparticles as mosquitocidal is less explored, hence in our study; we have attempted to provide the missing link to uncover the potential use of Zinc oxide nanoparticle for the mosquito control.

It is well known that human consciousness phenomena can make possible changes while human interaction and the behavior of humans can also change but is it possible that how human consciousness can affect the matter also is a significant question for the future of science [23]. From the current research point of view the role of human consciousness and how it affects the matter at nano level could be a cumulative effect, therefore more research is warranted at quantum biology level for confirmation. Systematically replicating and extending these findings on other nano syntheses could be an eye-opener for many disciplines [24-30].

\section{Materials and Methods}

\section{Experimental Design}

In the present study, our aim is to synthesize Zinc oxide Nanoparticle using Aloe vera plant extract and to test its efficacy against Culex quinquifasciatus larvae and also observe how the amalgamation of Laser technology can affect the geometry of nanoparticles. The main aim of the study lies in the fact that how human consciousness can affect the nanosynthesis?

\section{Preparation of Gel Extract of the Aloe barbadensis Mill. (Aloe vera):}

Aloe vera leaves were collected from the Botanical garden of the DEI campus Agra, India. They were washed under tap water and dried at room temperature. The leaves were peeled off and the gel part was collected in the beaker and accordingly $10 \%$ aqueous solution was prepared, as suggested by other experimentation $[30,31]$ the solution was heated between $75^{\circ} \mathrm{C}-85^{\circ} \mathrm{C}$ for $30 \mathrm{~min}$. on magnetic stirrer cum hot-plate (Figure S1) after that it was cooled at room temperature and then filtered using Whatman filter paper [32].

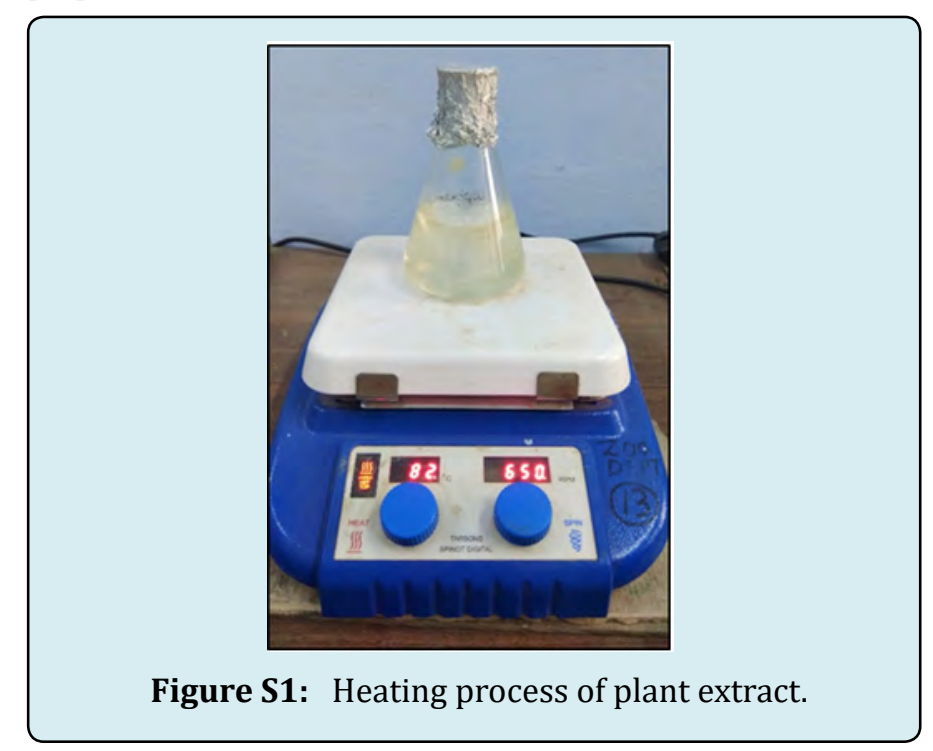

\section{Synthesis of Zinc oxide Nanoparticle}

$50 \mathrm{ml}$ of the prepared $10 \%$ aqueous gel extract was heated at $80^{\circ} \mathrm{C}$ for 20 minuteson a magnetic stirrer-cum hot plate. To the extract, $0.25 \mathrm{M}$ Zinc nitrate solution was added using micropipette. The solution was then allowed to cool and stored at room temperature in dark. The solution was light yellowish in appearance after synthesis.

\section{Characterization of the Synthesized Zinc Oxide Nanoparticle}

Ultraviolet and visible (UV-Vis) absorption spectroscopy was performed to record the absorption spectra of the nanoparticles within the range and to check whether the solution was in dispersed form or in agglomerated form. The absorption spectra of the diluted sample were recorded in a range between $200 \mathrm{~nm}-500 \mathrm{~nm}$ using UV-Visible spectroscopy on a Shimadzu UV-1800Spectrophotometer. The dried powdered sample was used for the analysis of the XRD spectrum by using D8 Advance Bruker Diffract meter for the identification of the crystalline lattice structure and purity of the synthesized nanoparticles. Particle size was determined by Dynamic Light Scattering technique using Malvern ZS90 instrument. All the characterization procedures were performed in the Chemistry Department of Dayalbagh Educational Institute Agra, India.

\section{Testing The Efficacy of The Mosquito Larvae}

Larvae of Culex quinquefasciatus mosquito were collected from the ponds of Botanical garden of the DEI campus, Agra. Larvae were washed in distilled water and were 
segregated according to different instars and the assessment of the larvicidal activity of prepared nanoparticles was tested following the standard protocol of the World Health Organization, 2005 [32]. The experiment was set up against $2^{\text {nd }}$ and $3^{\text {rd }}$ instar larvae taking 25 larvae in $100 \mathrm{ml}$ of distilled water in various beakers (Figure S2) kept at room temperature and other optimal environmental conditions in our lab. After that different doses of the synthesized nanoparticles were introduced into the beaker and \% mortality was recorded after $24 \mathrm{~h}$ and $48 \mathrm{~h}$ in each case.

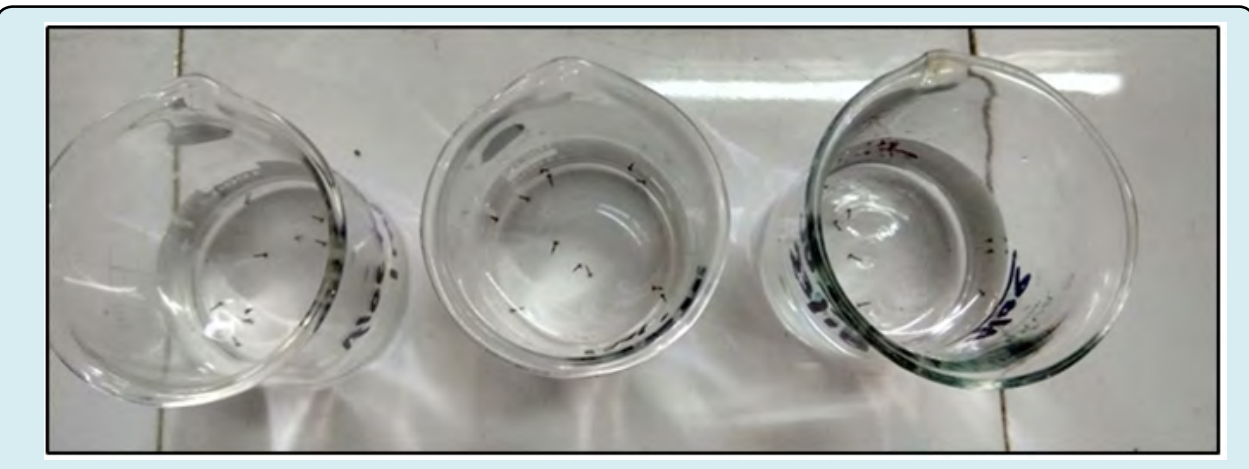

Figure S2: Setup for testing efficacy of Culex larvae.

\section{Testing the laser Radiation Effect and Human Consciousness Phenomena}

Synthesized ZnO NPs present in the beaker were kept in a small box covered by a black sheet for obstructing the penetrance of the natural light, after that Laser light having wavelength range $630 \mathrm{~nm}-680 \mathrm{~nm}$ was suspended from the ceiling of the box and was left for few hours (Figure S3), the experiment was conducted at optimal environmental factors in our lab.

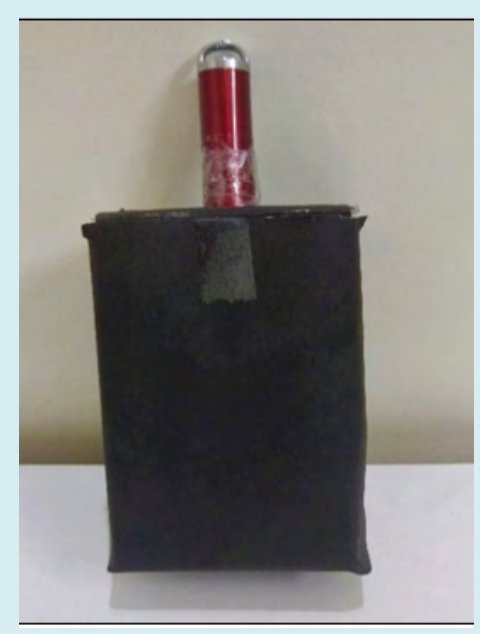

Figure S3: Setup for Laser radiation effect without human observation.

Similarly, another set up was kept simultaneously with the previous one but this time synthesized ZnO NPs were directly kept in the beaker which was covered by a black sheet for obstructing the penetrance of the natural light but was kept open from above and the Laser light having wavelength range $630 \mathrm{~nm}-680 \mathrm{~nm}$ was attached to the beaker (Figure S4) so that we can easily observe it with concentrated human eye and focusing and can observe the effect of human consciousness phenomena.

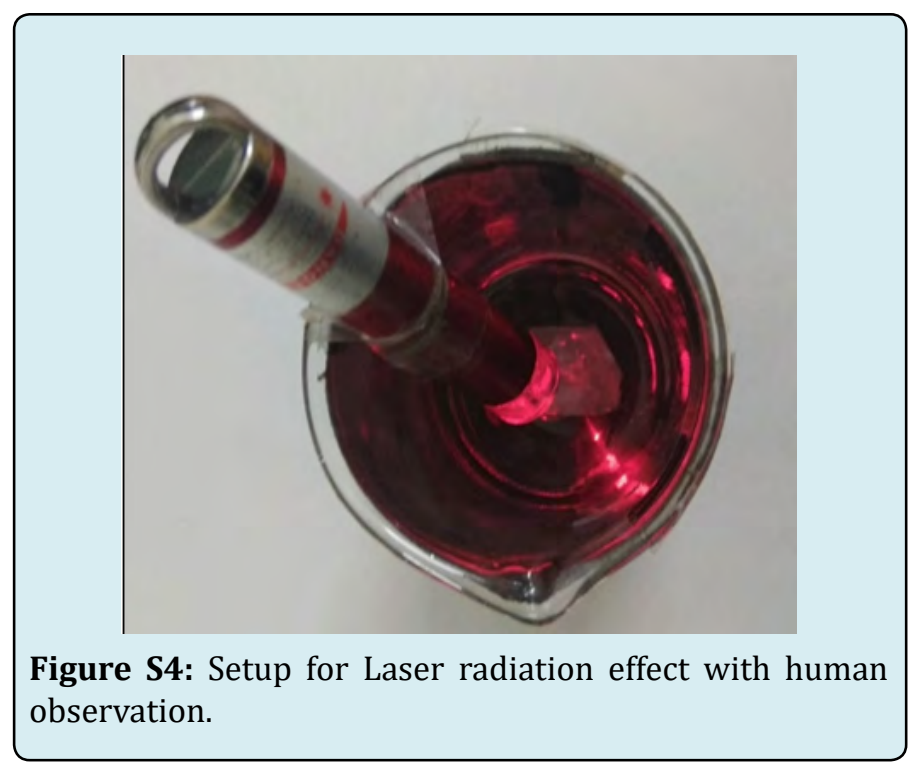

\section{Results}

\section{X-Ray Diffraction (XRD) Analysis of Zinc Oxide Nanoparticles}

The diffraction pattern (Figure 1) shows that following peaks were observed at $31.79^{\circ}, 31.42^{\circ}, 36.52^{\circ}$ of $2 \theta$ which corresponds to (100), (002), (101) crystal planes respectively and the data was in good coordination with the standard diffraction card of JCPDS - 36 - 1451 for Zinc oxide nanoparticles. 


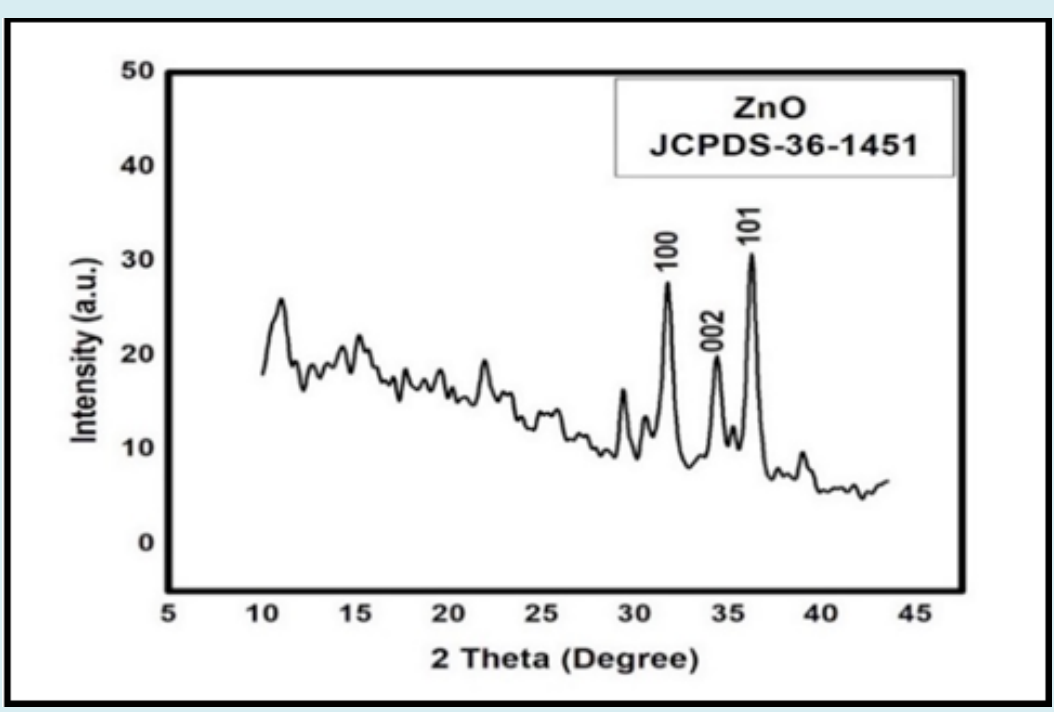

Figure 1: Showing XRD pattern of Zinc oxide Nanoparticles.

\section{Ultra Violet Visible Spectroscopy (UV-Vis Spectroscopy) Of Zinc Oxide Nanoparticles}

The absorption spectra of the diluted sample were recorded in a range between $200 \mathrm{~nm}-500 \mathrm{~nm}$. The highest absorbance peak of the normally synthesized nanoparticles was observed at $309 \mathrm{~nm}$ (Figure 2A), while there was variation in the absorption spectra when the nanoparticles were kept under Laser irradiation effect without any human observation, highest observation peak was observed at 309 $\mathrm{nm}$ (Figure 2B). The absorption spectra varied significantly for the nanoparticles when kept under Laser irradiation effect with human observation and the highest peak was observed at $312 \mathrm{~nm}$ (Figure 2C).

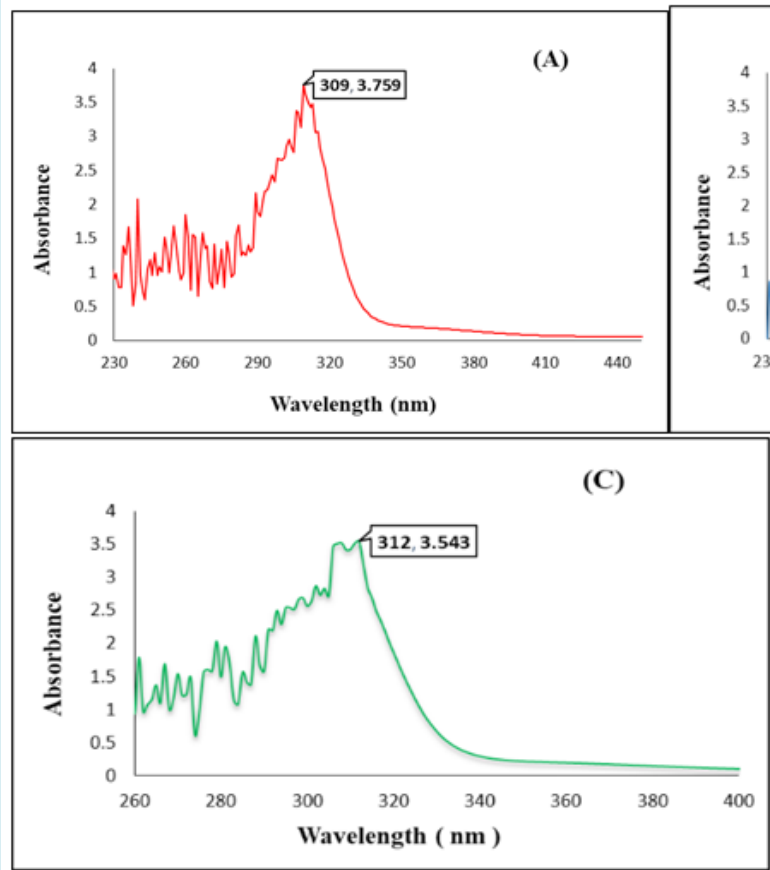

(B)

Figure 2: UV-Vis Spectra of: A) Synthesized ZnO NPs; B) ZnO NPs after laser effect without human observation; C) ZnO NPs after laser effect in human observation. 


\section{Dynamic Light Scattering (DLS) Analysis Of Zinc Oxide Nanoparticles}

The average particle size of $\mathrm{ZnO}$ nanoparticles was 465.7 nm (Figure 3A) and also the intensity was high throughout the scanning from which we can infer that the nanoparticles were present in the highly agglomerated form. It was observed that after Laser irradiation effect without any human observation average particle size of the nanoparticles increased i.e. $675.3 \mathrm{~nm}$ and the graph recorded was also discontinuous (Figure 3B) but it was observed that the average particle size after Laser irradiation effect in human observation decreased i.e. $376 \mathrm{~nm}$ (Figure 3C), from this observation we can infer that human consciousness/ brain waves phenomena with cumulative effect of Laser irradiation can change the physical and geometrical properties of the nanoparticles. The symmetrical nanoparticle synthesis happening due to brain waves of consciousness which are very subtle but found effective in altering the geometry of ZnO nanoparticles.

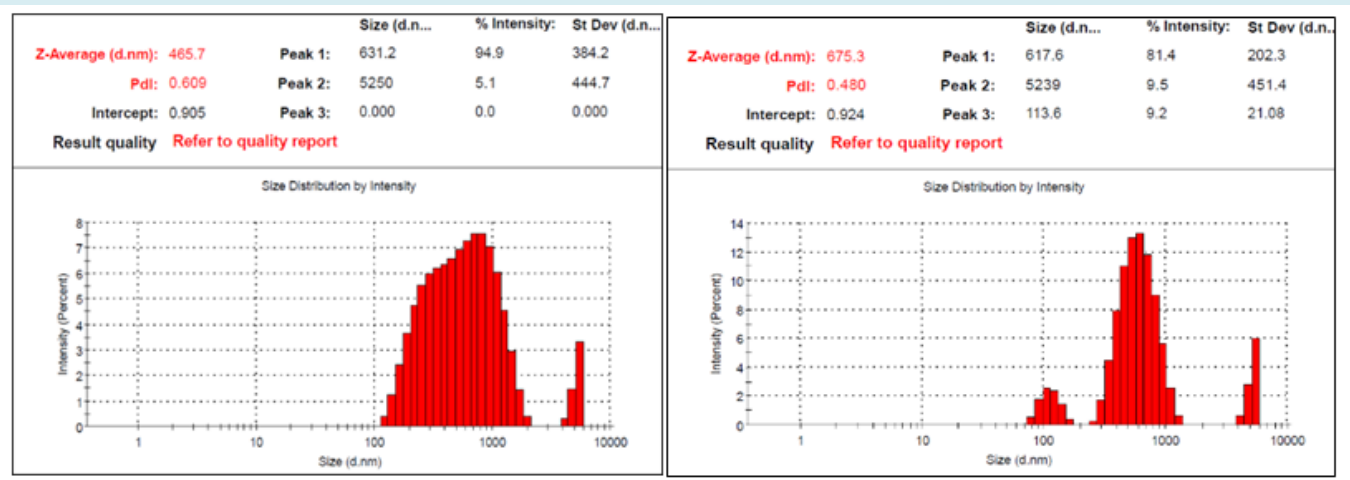

(A)

(B)

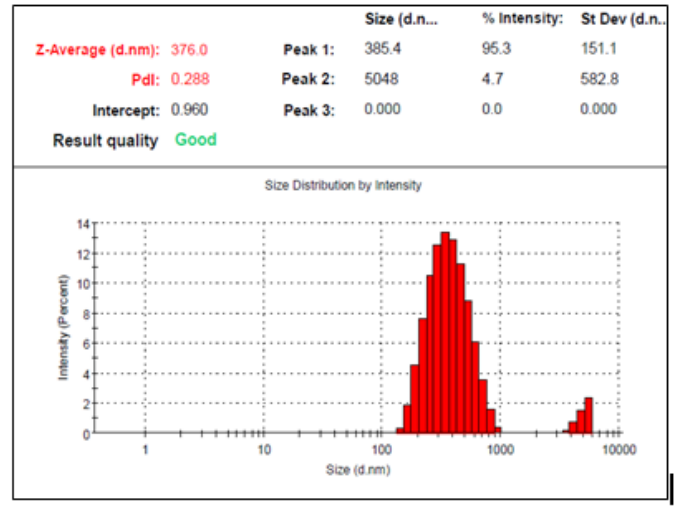

(C)

Figure 3: DLS analysis of: A) Synthesized ZnO NPs; B) ZnO NPs after laser effect without human observation; C) ZnO NPs after laser effect in human observation.

\section{Bioassay and Data analysis}

The obtained toxicity data was tabulated in MS Excel and average mortality was calculated. Statistical technique regarding the estimation of \% mortality, Probit of kill and $\mathrm{LC}_{90}$ were calculated by using Probit analysis and Finney's table [24].

A comparative probit regression graph was generated for bioassay result after $24 \mathrm{~h}$ and $48 \mathrm{~h}$ of exposure (Figure 4). Probit equations were generated from the data, $\%$ mortality calculated was $48 \%$ and $96 \%$ at $24 \mathrm{~h}$ and $48 \mathrm{~h}$ for $3 \mathrm{ml}$ dose concentration and $\mathrm{LC}_{90}$ value was estimated at 2.44 of test concentrations of $\mathrm{ZnO}$ NPs after 48h. The coefficient of determination $\left(\mathrm{R}^{2}\right)$ was 0.994 and 0.944 for $24 \mathrm{~h}$ and $48 \mathrm{~h}$ respectively which indicated the reliability of data and the high fitness of regression line for the obtained data on the plot (Tables 1\&2). 


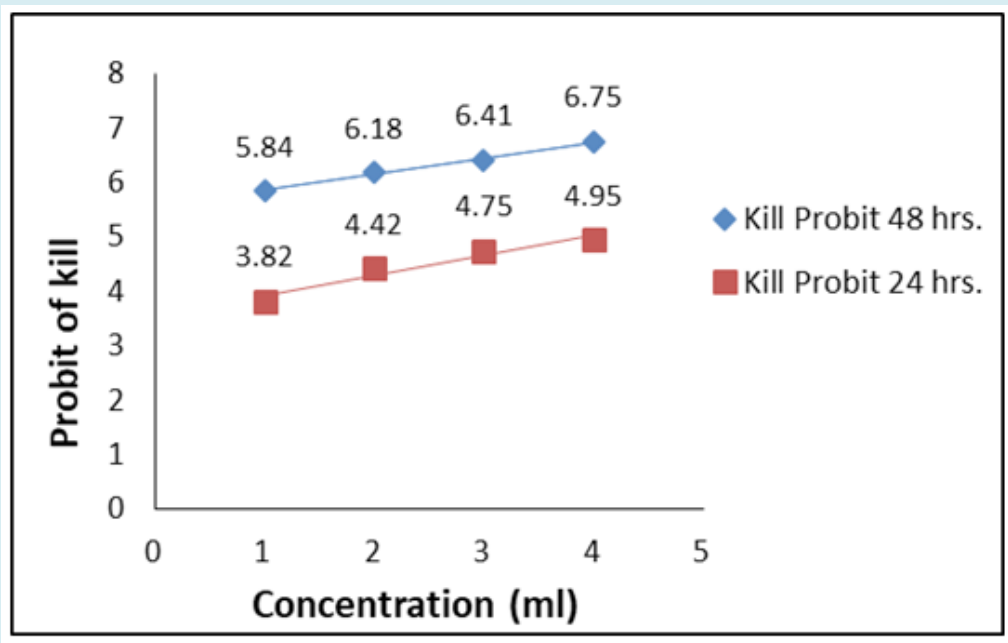

Figure 4: Relation between Probit of kill and concentrations of ZnO NPs after $24 \mathrm{~h}$ and $48 \mathrm{~h}$.

\begin{tabular}{|c|c|c|c|c|}
\hline $\begin{array}{c}\text { Concentration of synthesized ZnO } \\
\text { nanoparticles }\end{array}$ & $\begin{array}{c}\text { \% Mortality } \\
\mathbf{( 2 4 h )}\end{array}$ & $\begin{array}{c}\text { \% Mortality } \\
\mathbf{( 4 8 h )}\end{array}$ & $\begin{array}{c}\text { Probit of kill } \\
\text { (24h) }\end{array}$ & $\begin{array}{c}\text { Probit of kill } \\
\text { (48h) }\end{array}$ \\
\hline $0.5 \mathrm{ml}$ & $12 \%$ & $80 \%$ & 3.82 & 5.84 \\
\hline $1 \mathrm{ml}$ & $28 \%$ & $88 \%$ & 4.42 & 6.18 \\
\hline $2 \mathrm{ml}$ & $40 \%$ & $92 \%$ & 4.75 & 6.41 \\
\hline $3 \mathrm{ml}$ & $48 \%$ & $96 \%$ & 4.95 & 6.75 \\
\hline
\end{tabular}

Table 1: Data of conc. of ZnO NPs and \% mortality after $24 \mathrm{~h}$ and 48 hours.

\begin{tabular}{|c|c|c|}
\hline \begin{tabular}{c} 
\% Mortality $\begin{array}{c}\text { after Probit equation } \\
(y=a+b x) \\
\mathrm{R}^{2}\end{array}$ \\
\cline { 2 - 3 }
\end{tabular} & $\mathrm{y}=0.372 \mathrm{x}+3.55$ & $\mathrm{48}$ hrs. \\
\cline { 2 - 3 } & 0.9945 & 0.9441 \\
\hline
\end{tabular}

Table 2: Data of Probit equation and R2 values after $24 \mathrm{~h}$ and 48 hours.

\section{Discussion}

While conducting this investigation we observed that Aloe vera synthesized ZnO NPs shows better efficacy at low concentrations which can be due to the smaller geometry and size of nanoparticle which is able to transport across the cuticle of the mosquito larvae.

From the characterization point of $\mathrm{ZnO}$ nanoparticles, we observed that the absorption spectra of UV-Vis Spectroscopy for all setups varied, hence from the results we can infer that the variation can be because of laser effect with and without human observation, by which we can conclude that laser and human consciousness may have affected the geometry of the ZnO NPs. XRD analysis of ZnO NPs was validated from the standard diffraction card no. JCPDS-36-1451, hence we can infer about the purity of ZnO NPs. The variation in the average particle size was analyzed by the DLS technique and from the results we can infer that the size of the nanoparticles could have increased due to internal stress and defects after laser effect without human observation and the reduction in size could be because of the human focusing and the energy radiated while observing with concentrated human eye and could also be possible because of exothermic reaction taking place in the medium itself.

The difference in the results due to human interference can be due to subtler consciousness phenomenon, which is being originated at a subtle energy level (i.e. at Planck's level) however, this outcome at nano level can be the cumulative effect. The role of consciousness as suggested by Nikola Tesla, et al. [25] to study the non-physical phenomena and that it will make progress in one decade, although in all previous centuries of its existence, this was in terms of energy, frequency, and vibrations. Also, Einstein has indicated that there is "spooky action at a distance" [26,27] and there are 
also other significant findings indicating the role of human consciousness which perhaps work at Planck's level $\left(10^{-35}\right)$.

\section{Conclusion}

The modern scientific studies have proved that human consciousness can affect the behavior of human beings however, no such studies are available how could it affect nano synthesis? Therefore study conducted will facilitate new divergence to this science and could be a milestone in this direction warranting more detailed study [28]. Theories of Quantum Mechanics observed where the entanglement of the observer's mind is essential for giving reality to the probability waves in nature [29]. This can provide promising physical explanation of consciousness. We, therefore report here for the scientific community to see the role of subtler energy of human consciousness in nano synthesis.

\section{Acknowledgment}

We sincerely acknowledge Prof P. S. Satsangi Sahab, Chairman, of Advisory Committee on Education, Dayalbagh Educational Institute (DEI), Prof. P.K. Kalra, Director, DEI for providing support and encouragements for the work. We wish to thank Prof. Sahab Dass, Dept. of Chemistry, Dayalbagh Educational Institute, for providing UV-Vis Spectroscopy, XRD and DLS facilities. We also thank Miss Shweta Yadav and Miss Savy P. Minal for their relevant support and help during the study.

\section{References}

1. Al Dhabi N, ValanArasu M (2018) EnvironmentallyFriendly Green Approach for the Production of Zinc Oxide Nanoparticles and Their Anti-Fungal, Ovicidal and Larvicidal Properties. Nanomaterials 8(7): 500.

2. Farooq WA, Ali SM, Tawfik W, Fatehmulla A, Aslam M, et al. (2014) Influence of laser irradiation on the optical properties of nano-sized powder of metal oxide. Russian Journal of Physical Chemistry A 88(13): 2446-2450.

3. Soni N, Prakash S (2012) Fungal-mediated nano silver: an effective adulticide against mosquito. Parasitology research 111(5): 2091-2098.

4. Soni N, Prakash S (2012) Entomopathogenic fungus generated Nanoparticles for enhancement of efficacy in Culex quinquefasciatus and Anopheles stephensi. Asian Pacific Journal of Tropical Disease 2: S356-S361.

5. Soni N, Prakash S (2012) Efficacy of fungus mediated silver and gold nanoparticles against Aedesaegypti larvae. Parasitology research 110(1): 175-184.

6. Soni N, Prakash S (2013) Possible mosquito control by silver nanoparticles synthesized by soil fungus (Aspergillusniger 2587). Adv Nanoparticles 2: 125-132.

7. Soni N, Prakash S (2014) Microbial synthesis of spherical nanosilver and nanogold for mosquito control. Annals of microbiology 64(3): 1099-1111.

8. Soni N, Prakash S (2015) Antimicrobial and mosquitocidal activity of microbial synthesized silver nanoparticles. Parasitology research 114(3): 1023-1030.

9. Soni N, Prakash S (2015) Different geometrical AgNPs for vector control and their added value of antibacterial activity. J Parasitol Photon 105: 232-243.

10. Minal SP, Prakash S (2016) $\mathrm{Cu}-\mathrm{Zn}$ and Ag-Cu bimetallic nanoparticles as larvicide to control malaria parasite vector: A comparative analysis. In Humanitarian Technology Conference (R10-HTC), pp: 1-6.

11. Minal SP, Prakash S (2018) Characterization and NanoEfficacy Study of Palladium Nanoparticles against Larvae of Anopheles stephensi (Liston). International Journal of Advanced Engineering and Nano Technology 3(10): 1-5.

12. Yadav S, Prakash S (2018) Effect of LASER on the Synthesis of Gold Nanoparticles with Reference to Geometries. Advances in Nanoparticles 7: 69-76.

13. Chaturvedi DK, Prakash S (2016) Role of Electric and Magnetic Energy Emission in Intra and Interspecies Interaction in Microbes_AJRC.

14. Chaturvedi DK, Prakash S (2016) The Consciousness in Mosquitoes. Journal of Mosquito Research, pp: 6.

15. Richa (2017) Study on possible measurement of Consciousness in microbes, mosquitoes, animals and man with special reference to Bio field. Dayalbagh Educational Institute, pp: 1-6.

16. Richa DK, Chaturvedi SP (2013) Consciousness Measurement Problem in Man, Mosquitoes and Microbes: A Review. Proceedings of the Toward a science of consciousness, TSC, pp: 3-9.

17. Richa DK, Chaturvedi S, Prakash (2014) The Possible Consciousness. In: Proceedings of the Toward a science of consciousness, TSC 2014. Arizona, USA.

18. Richa DK Chaturvedi, Prakash S (2015) Bio electromagnetics in microbes and mosquitoes: a comparative study with special reference to biofield. In: Proceedings of the toward a science of consciousness, TSC 2015. Helsinki, Finland.

19. Prakash S (2017) The Science Of Quantum Soul And A 
New Theory Of Consciousness Study? The $24^{\text {th }}$ annual conference on 'The science of consciousness' (TSC), June 5-10, 2017. La Jolla, California, USA, pp: 260.

20. Prakash S (2017) Microcosm \& Macrocosm-A Relationship Study On Quantum Consciousness. The $24^{\text {th }}$ annual conference on 'The science of consciousness' (TSC), June 5-10, La Jolla, California, pp: 261.

21. Soam Prakash (2017) An Analysis of Bio field As a Parameter 0 Wellness and Consciousness: A Squid Based Meg Study'. The $24^{\text {th }}$ annual conference on 'The science of consciousness' (TSC), La Jolla, California, USA, pp: 113.

22. Prakash S (2018) Parallel Universe are Quantum States of Big Bang at Macrocosm? A Validation of Hamer offPenrose Tubulin Consciousness Model at Microcosm'. The $25^{\text {th }}$ annual conference on 'The science of consciousness' (TSC), The University of Arizona- Centre for consciousness studies, USA, pp: 216.

23. Radin D, Michel L, Galdamez K, Wendland P, Rickenbach $\mathrm{R}$, et al. (2012) Consciousness and the doubleslit interference pattern: Six experiments. Physics Essays 25(2).

24. Finney D J, Tattersfield F (1952) Probit analysis. $2^{\text {nd }}$ (Edn.), Cambridge University Press; Cambridge, USA, pp: 318.

25. Raković D (2006) Tesla and quantum-coherent states of consciousness: Case study for understanding quantumholographic nature of creativity. Proc. Ideas of Nikola
Tesla, ASA RS, Banja Luka.

26. Einstein A, Podolsky B, Rosen N (1935) Can quantummechanical description of physical reality be considered complete? Physical review 47(10): 777.

27. Salart D, Baas A, Branciard C, Gisin N, Zbinden H (2008) Testing the speed of spooky action at a distance. Nature 454(7206): 861.

28. Satsangi PS, Hameroff S (2016) Consciousness: Integrating Eastern and Western Perspectives. ND: New Age Books, pp: 282-311.

29. Shanker A, Popov K, Madsen C, Girish N (2015) Wave Mechanics of the Mind-C-7, TSC, 2015, Arizona, USA.

30. Parthasarathy G, Saroja M, Venkatachalam M (2017) Biosynthesized nano-formulation of Zinc oxide-Aloe vera and to study their characterization and antibacterial activities against multiple pathogens. International Journal of Pharmaceutical Sciences and Research 8(2): 900.

31. Sangeetha G, Rajeshwari S, Venckatesh R (2011) Green synthesis of Zinc oxide Nanoparticles by Aloebarbadensis miller leaf extract: Structure and optical properties. Materials Research Bulletin 46(12): 25602566.

32. World Health Organization (2005) Guidelines for laboratory and field testing of mosquito larvicides (No. WHO/CDS/WHOPES/GCDPP/2005.13). World Health Organization, Geneva. 